\title{
Visões do mar na \\ literatura angolana contemporânea
}

Tania Celestino de Macêdo*

* Universidade de São Paulo e Universidade E stadual Paulista - Campus de Assis. 
Fonte de numerosas imagens, o mar tem lugar de destaque no discurso literário, sobretudo no mundo de língua portuguesa. Aí, por se constituir na via líquida por onde singraram as caravelas chegando aos mais distantes portos, ele se tornou símbolo do alargamento dos domínios portugueses, criando o fenômeno crucial do "ser português": o I mpério. Sob essa perspectiva, pode-se mesmo dizer que as águas salgadas foram o ponto privilegiado de onde a nação mirou-se ao voltar seu olhar ao Outro, engendrando, a partir da espessa camada de representações elaboradas sobre os povos dos portos, uma imagem de si própria.

Dessa maneira, em uma intrincada rede de representações superpostas, revistas e ampliadas, o olhar oriundo das naus fez com que os portos onde elas chegaram fossem vistos, mas não se fizessem visíveis e que as vozes ali ouvidas não fossem plenamente audíveis. Se as imagens criadas eram encharcadas de mar e explicitavam o poder das caravelas, pode-se afirmar que no confronto entre olhares e vozes foram sendo moldadas novas visões, de tal maneira que o ponto de vista da caravela foi por muito tempo o que enformou os portos, acabando por se tornar parte de seu imaginário.

Sob a perspectiva dos portos, fazia-se necessária uma outra viagem: aquela que propiciasse uma real descoberta de si próprios, tentando deslindar as imagens superpostas e tornar audíveis suas falas. E m outras palavras, tentar resgatar a memória e os sonhos. Nesse processo, foi fundamental o papel da literatura pois, como ensina o mestre Alfredo B osi, "as relações entre os fenômenos deixam marcas no corpo da linguagem" (BOSI , 1992:11) e o discurso articulado na série literária, ao abrir-se em possibilidades de projetar o futuro, foi o aliado escolhido na árdua luta que se travou para a independência. 
Em Angola, mais precisamente na cidade de Luanda, porto a que as naus dos colonizadores portugueses chegaram no século XV e de onde partiriam apenas em 1975, o caminho percorrido rumo à independência - a "contra-viagem" - foi longo e demorou um largo tempo para que suas próprias imagens e vozes se impusessem. Zagaias, depois toscas armas de fogo e finalmente as rajadas das kalachinikov dos anos 1960 fizeram-se ouvir, alterando a situação: os até então donos do mar e da voz seriam calados e em seu lugar, triunfante, a voz dos reais donos da terra, há tanto silenciada, erguer-se-ia, proferindo discursos de autonomia e construção de uma nova nação.

Assim, sobretudo a partir dos anos da luta armada de libertação, houve a negação das imagens e sons das caravelas ${ }^{1}$ até que, de forma madura, paulatinamente foi possível reconhecer que o mar também forjou um dos veios da memória possível do passado mas que a sua posse deveria ser realizada.

Para examinarmos esse processo, escolhemos inicialmente uma narrativa, "Náusea", que consideramos paradigmática do período de consolidação da literatura angolana, quer pelo fato de seu autor, Agostinho Neto - o mais importante articulador do processo de luta que levaria à independência de Angola - explicitar em seus textos o papel fundamental da literatura como uma das estratégias de confronto com o colonialismo, quer por se tratar de um conto bem elaborado em que há uma busca de expressão de valores nacionais e a construção de uma personagem-protagonista cujos traços fundamentais seriam retomados posteriormente em diversos textos de outros autores angolanos.

O conto de Agostinho Neto, publicado em 1961, apresenta-nos como personagem-protagonista o velho J oão, trabalhador humilde e morador do musseque, a favela luandense, o qual vai visitar sua família na ilha de Luanda. É curioso notar que na descrição do reencontro da personagem com o espaço de sua infância, que ocupa a parte inicial da narração, tem-se o ambiente marítimo dado somente através de metonímias: "sombra dos coqueiros", "areia quente da praia", e "uma ou outra onda mais comprida", como se o vocábulo MAR devesse ser evitado. Na verdade, ele só ganhará substancialidade quando o velho morador do musseque tomar a palavra: “O mar. Mu'alunga!”, para acrescentar: "O mar. A morte. Esta água salgada é perdição." A seguir, o texto enumera as mortes de pescadores da família e de amigos do velho J oão que se afogaram, como espécie de prova dos malefícios trazidos pelo mar. Ocorre, porém, que a esfera da individualidade alarga-se quando, através do "discurso citado antecipado e disseminado" (BAKHTIN, 1981:167) a voz narrativa organiza e abrevia o conteúdo dos pensamentos do ve-

A respeito das imagens e perspectivas do mar na poesia angolana, remetemos ao trabalho de Carmem Lúcia Tindó Secco (SECCO, 1996) 
Iho J oão, propiciando que as queixas da personagem sejam ampliadas com as lentes do discurso dos marginalizados dos portos em face da chegada das caravelas: “K alunga. D epois vieram os navios, saíram os navios. E o mar, é sempre K alunga. A morte. O mar tinha levado o avô para outros continentes. O trabalho escravo é Kalunga. O inimigo é o mar." (p. 54 )

Cremos que essa última imagem é bastante significativa do que acima afirmávamos: o mar é aqui identificado aos navios e às desgraças da colonização, entre as quais avulta o tráfico negreiro e, portanto, é caracterizado como I nimigo: "não conhece os homens. Não sabe que o povo sofre. Só sabe fazer sofrer." (p. 54)

A equivalência do mar à desgraça é operacionalizada, na esfera das expectativas da personagem, como fatalidade contra a qual não ela pode lutar, apenas enojar-se; mas, levando em conta que a náusea é também a expressão da revolta do colonizado, é possível realizar uma leitura em que a consciência possível do velho J oão é ultrapassada, vislumbrando as possibilidades de uma mudança da situação.

Tendo em vista a eloqüência do texto e o papel seminal desempenhado por Agostinho Neto na formação do sistema literário angolano, causa espécie verificar que o mar, como imagem privilegiada, não mais tenha destaque na ficção de Angola até os anos 1990. Ainda que os traços constitutivos de velho J oão tornem-se matrizes de constituição de numerosas personagens de narrativas produzidas entre os anos 1960 e 1980, como a velha quitandeira Nga Palassa (J ofre R ocha), vovô Petelu e vavó Xixi (Luandino Vieira) ou vavô Bartolomeu (Antônio J acinto), os contos, novelas e romances realizad os nesse períod o focalizarão apenas o musseque de L uanda, voltando as costas para o oceano.

Segundo entendemos, esse movimento tem em vista contrapor ao mar um outro espaço, construindo a partir dele uma nova imagem que, veiculada literariamente, dê voz e vez ao colonizado. Dessa forma, surge na prosa angolana a partir dos anos 1960 a focalização do musseque. Será nesse espaço narrativo em que se forjarão imagens de um novo homem, disposto a lutar por sua dignidade e sua liberdade ${ }^{2}$, negando o discurso das caravelas para fazer audível a fala da terra.

Dos numerosos textos da "prosa do musseque" produzidos no período de 20 anos (1960-1980), um deles merece destaque, por ser o único a articular duas imagens: o bairro sub-urbano luandense e o mar. Trata-se de "Pedro Caliota, sapateiro andante", de osé L uandino Vieira, narrativa produzida em 1971 e presente em Macandumba.

Serão mais de uma centena de textos que terão como o cenário os musseques de Luanda, o que nos levou, por ocasião de nossa tese de doutoramento, intitulada "D a fronteira do asfalto aos caminhos da liberdade (imagens de L uanda na literatura angolana contemporânea) (1993), a batizar esse grande conjunto de textos como "prosa do musseque". 
A novela, a partir das andanças do protagonista Pedro Caliota, sapateiro de profissão tornado porém pescador ocasional em razão das vontades de sua esposa grávida, focaliza toda a cidade de L uanda, em um movimento inusitado para a produção literária do período, pois não apenas o musseque, de onde provém a personagem, mas os vários bairros da Baixa - a cidade do colono - e o mar, tornam-se cenário para o Quixote que tenta combater não imaginários moinhos de vento, mas o estigma de negro morador da periferia da cidade colonizada. É importante salientar que nesse texto de L uandino o mar apresenta um caráter dúbio, pois é o celeiro de onde provém os peixes que Caliota venderá e a morada da estranha garoupa negra, em cujo ventre o sapateiro-pescador encontrará uma nota de 500 escudos, mudando-Ihe a sorte. É contudo, também, o lugar de uma pescaria feita com sangue (já que a personagem só obtém os peixes quando embebe no sangue de seus dedos o anzol antes de o lançar às águas) e o espaço que receberá, no fim do dia, o corpo do negro assassinado por populares porque esbarrara, na rua, em uma mulher branca que o acusa de tarado e terrorista:

O tiro mais primeiro. Depois o salto. F imba de mentira no sono das águas da baía. Um quieto nadar de agulha, fimba de pedra, braçadas do medo, coragem dele de mentira saindo no sangue, incendiando toda a tarde de sol poente. (...)

Voltando nos casos: Caliota, pobre pedro ou moisés morto nas águas, quem que pensava era imortal em sessenta-e-um? Bóia silencioso já, lá vai, o ió uia, sombras da noite da Ilha não vão receber nunca mais. (p. 52)

Vida e morte, alimento e túmulo, o mar no texto de Luandino Vieira não apresenta uma imagem única; ao contrário, a partir de um discurso opaco, constrói perspectivas múltiplas, que se sucedem, deixando ao leitor numerosas pistas de interpretação: os elementos da natureza (árvores, águas, sol, animais) são benéficos e inimigos e apenas uma leitura atenta permite ver que imagens oriundas dos portos e das caravelas constituem o imaginário com que se tece a narrativa. Dessa maneira, a K ianda ( figura mítica africana) e N ossa Senhora ( a mãe de J esus no imaginário cristão) orientam simultaneamente as ações da personagem, assim como Dom Quixote (romance ocidental) e os mi-sosso (contos tradicionais africanos) constituem o intertexto do relato. $O$ único fato inquestionável éa presença do colonialismo, a partir do qual a palavra proferida por uma branca tem força de verdade e leva à morte um trabalhador negro. A desconstrução dessa "verdade", no texto, é dada a partir do tempo cronológico, referido várias vezes no texto: o ano de 1961, o qual, no contexto situacional de Angola marca os numerosos massacres de que foram vítimas os moradores dos musseques, em represália ao início da luta armada de libertação deflagrada por nacionalistas na capital do país. 
A essa luz, podemos afirmar que a narrativa de Luandino Vieira desenha uma síntese entre imagens oriundas dos portos e das caravelas em seu texto, apontando porém para a necessidade que o fato colonial tenha término, para que outras estórias possam ser escritas.

Com uma perspectiva algo diversa de "Pedro Caliota, sapateiro andante", temos Memóri a de mar, de M anuel Rui, escrito em 1978, portanto três anos após a independência de Angola. Nessa narrativa, próxima ao fantástico, dada a sobreposição de tempos e a viagem exploratória que nele as personagens realizam, temos inicialmente a mesma imagem negativa do elemento marítimo veiculada em "Náusea", pois no romance de Manuel Rui um submarino, repleto de contra-revolucionários que impediriam a independência de Angola, é avariado e a sua exploração, por soldados e cientistas angolanos, em um futuro indefinido na narrativa, revela o conteúdo da embarcação:

Porcelanas das Índias, condecorações de ouro, pratas, dentes de elefante, pedras preciosas, o próprio testamento de Diogo Cão. (...) e uma biblioteca com livros "a maioria deles dedicados à tática e estratégia de navegar e penetrar no continente. Nem um só livro científico escrito numa das línguas originárias do continente. (p. 108, 110)

O texto reitera a relação submarino/“mar português" quando, parodicamente, refere-se ao episódio do Velho do R estelo, de Os Lusíadas no seguinte trecho “havia vestígios do levantamento que o primeiro-tenente encabeçava visando contrariar a navegadora e peregrina idéia dos donos do submarino. Ele e os seus marinheiros opuseram-se à navegação e tentaram, mesmo a bordo, dedicar-se à atividade inicial: a agricultura" (p. 109) ou quando, no capítulo 16, a tripulação metamorfoseia-se, e o capitão da embarcação "Entrou no salão envergando um manto vermelho de vice-rei das índias, sapato de fivela e meia alta branca (...)" identificando-se como "O vice-rei das Í ndias e trago por missão continuar a nossa epopéia dos descobrimentos" ( p. 99-100).

O mar no texto de Manuel Rui é, pois, inicialmente, o império do submarino colonialista e com ele identificado. A diferença que encontramos com relação ao texto de Agostinho N eto é que o romance produzido em 1978 aponta para a necessidade de uma nova viagem, exploratória, que traga à tona a embarcação avariada:

Primeiro foram os mergulhos inconseguidos, a expectativa, a ânsia de descobrir o submarino afundado. Depois a euforia. A idéia de justiça e vingança: trazer o submarino para terra! E havia tanto que vingar! Mas, pouco a pouco, (...) tudo isso se diluiu, restando em nós um sentimento de profundo amor pela investigação. (p. 105-106). 
Ou seja, paulatinamente instaura-se a serenidade em lugar da vingança e, portanto, o reconhecimento da necessidade de recuperar as imagens do passado guardadas naquela nau, para poder melhor entender o presente. Na perspectiva de leitura que adotamos, Memória de mar, nesse momento, avança uma perspectiva de focalização do passado colonial diversa dos textos antes referidos, na medida em que a história não será negada e sim investigada e entendida, e, após esse processo, capacitará os indivíduos a elaborarem no presente novas imagens, novas vozes. Dessa forma, constrói-se outra forma de mirar o elemento líquido, depois de um mergulho na História: trazendo "os bolsos vazi os do ódi o que descarregávamos no fundo do mar olhado sempre como generosa testemunha de segredos" (p. 111). (G rifamos) Não são mais as imagens das desgraças veiculadas por velho J oão que darão o tom da narrativa; mas sim o NOVO: as crianças - os pioneiros -, de cujos "olhos desprendia-se um tempo tão luminoso como o sol refletido na transparência das águas do mar" (p. 116) (Grifamos). Ou seja, nessa narrativa elaborada três anos após a independência de Angola, o mar tornar-se-á a imagem luminosa de um futuro imaginado para a jovem nação. Infelizmente, porém, o porvir enfrentaria águas muito revoltas.

Sob a perspectiva de impacto do real sobre o imaginado (quando, passada a euforia da proclamação da independência a guerrilha interna e o auxílio da África do Sul aos inimigos do governo levaram a empregar todos os recursos da nação no esforço de guerra, ao mesmo tempo em que a corrupção começou a grassar), a literatura angolana procurará por respostas, buscando construir em suas páginas um novo discurso sobre o país. Deixadas as imagens do musseque que se identificavam à luta pela independ ência, o centro da cidade de Luanda será focalizado, e por suas ruas caóticas perambularão personagens bastante diversas dos heróis positivos de outro momento.

Dentre os textos com essas características merecem destaque duas narrativas de Pepetela: O cão e os calús, escrito em 1980, e O desejo de Kianda, produzido em 1993.

O primeiro deles constitui uma espécie de crônica sobre a cidade de L uanda elaborada a partir do inquérito realizado por um escritor sobre as andanças de um cão que percorre a cidade. O recurso de focalizar a deambulação do animal junto aos vários donos ocasionais, possibilita que o narrador insira em seu relato as vozes de numerosas personagens - oriundas de diferentes camadas sociais - e descreva o cotidiano da cidade. O panorama resultante desse mergulho nas ruas da capital angolana mostra o enraizamento, em todas as instâncias, do "esquema" (expressão que identifica pequenos e grandes atos de corrupção).

Se a cidade é o cenário privilegiado, o mar, no entanto, não se ausenta de 0 cão e os calús. E le se acha inscrito desde os primeiros momentos do relato através de uma das dedicatórias do texto a uma toninha, ser marítimo que espalha "espu- 
ma pelos oceanos da vida" e, paulatinamente, desenhar-se-á como equivalente de uma força popular positiva capaz de sobrepor-se aos donos do poder e aos discursos "revolucionários" usados para mascarar os interesses individuais.

Veja-se, por exemplo, a passagem que descreve o desfile de um bloco popular extremamente pobre, não utilizador do "esquema" e que, no entanto, acompanhado festivamente pelo Cão, obtém a vitória no Carnaval de rua de Luanda:

A canção falava da kianda, da jamanta, da calema, do oceano que é mãe, e daquela ilusão com cabelos de alga que só aparece uma vez na vida" (...) A multidão, contemplando a cena e embriagando-se do cheiro da maré vazia e da sensualidade das ondas, guardou silêncio religioso, fascinado. De repente, a calema acumulada na multi dão rebentou em mil vagas poderosas. Os aplausos não tinham fim, o povo abandonou as filas e foi dançando atrás do grupo, a beijar o ritmo do mar. (p. 101) (G rifamos)

A "calema" popular, onda que rompe os limites que se the querem impor, e extravasa sua alegria, metaforiza a teimosa esperança que se faz longe dos palanques oficiais e dos discursos do poder.

É curioso notar que, diferentemente dos outros textos até o momento citados, o opositor, no livro, encontra-se em terra: trata-se de uma árvore, a buganvília, a qual é comparada a das personagens, um sitiante e comerciante explorador do trabalho semi-escravo e utilizador do "esquema": "a buganvília é a planta mais linda que há; e que é como ele. Não percebi, mas ele referia-se ao crescimento contínuo" (p. 52).

E é dessa maneira que o confronto final oporá o Cão - transformado na narrativa em símbolo de valores de moralidade, esperança e paz - à buganvília, árvore tentacular, destruidora de toda a outra vegetação e representante, em nossa perspectiva de leitura, da corrupção que sufoca os alicerces do edifício nacional. A destruição total da buganvília, graças à presença de um trabalhador explorado que se revolta contra as ordens do patrão e auxilia o Cão, moribundo, na destruição das raízes, reitera a esperança várias vezes apontada no texto, a qual se consubstancia no olhar final ao elemento marítimo:

Deve ter rastejado toda a noite, porque o Sol nascente encontrou-o trinta quilômetros à frente, deitado de vez na areia do ancoradouro do K apossoka, as patas na água do mar, os olhos fixos na língua verdeamarela dos coqueiros do Mussulo. Procurando, num gesto derradeiro para lá do mar, o vulto duma toninha, algas como cabelos? (p. 186)

O outro texto de Pepetela a que nos referimos, $\mathrm{O}$ desejo de Kianda, também apresenta uma visão positiva do mar pois é o oceano que possibilita a liberdade 
plena da K ianda, sufocada entre os prédios do largo do Kinaxixi em uma cidade decadente, corrupta e palco de alianças espúrias tendo em vista o ganho fácil e o poder. Sob esse aspecto, essa narrativa de Pepetela apresenta ainda um fato inusitado na literatura angolana que se produziu desde os fins dos anos 1960: a destruição da cidade de Luanda. Em todas as narrativas até esse momento, a capital angolana sempre havia sido preservada como espaço da esperança, espécie de síntese da utopia do país que se tencionava construir. Ora, a libertação da K ianda que provoca o ruir dos prédios e a transformação da cidade em um rio que correrá rumo ao mar, simboliza a própria desesperança com os rumos de todo um processo, apontando para a necessidade de um recomeçar. E , curiosamente, esse início estaria nos caminhos do mar.

Trata-se, como se pode verificar, de uma perspectiva absolutamente nova no que tange à imagem do mar na literatura produzida em Angola. Não se trata mais de apontar a morte trazida pelas naus dos colonizadores, mas de buscar uma outra via que se abra para o exterior, perscrutando saídas para o impasse de um projeto exaurido.

Sobre esse particular, cremos ser importante apontar que um dos mais recentes romances angolanos publicado, Ri oseco (1997), de M anuel Rui, tenha como cenário inicial exatamente o ancoradou ro da Kapossoka, local que marcava a morte do Cão, protagonista de O cão e os calús.

Na narrativa de M anuel Rui, o grande eixo da narrativa é o aprendizado a ser feito por uma mulher do interior, Noíto, nascida no sul de Angola, mas sabedora das muitas línguas faladas no país. Ela deve apre(e) der o mar quando, fugindo da guerra com seu marido, um carpinteiro, passa a residir na ilha do Mussulo. A contraposição entre o "mato" e o litoral, propicia que se misturem vocábulos de línguas do sul (sobretudo o umbundo) e da capital (expressões da gíria luandense e do quimbundo), redundando em perspectivas diversas que se harmonizam na paz do M ussulo e apontam para o todo heteróclito que é a nação angolana formada por várias etnias.

É, no entanto, o amor pelo mar - expresso pelo narrador e pelas personagens - que torna esse romance bastante diverso de outros produzidos na literatura do país. E, sob esse aspecto, a seguinte definição do elemento marítimo dado pelo esposo de Noíto como que encerra um ciclo começado com "Náusea":

O mar é só assim por causa dos rios que lhe trazem a água. Os rios é que enchem o mar. Nenhum dia viste um mar encher um rio, já falei. Isto é tudo água que vem da nossa terra. Sem a nossa terra, sem os rios que atravessam muito tempo, devagar e depressa, depressa e devagar, a secar e a encher na chuva, onde é que estava o mar? Sem a nossa terra, 
onde nascem os rios, o povo daqui não tinha mar para pescar. Não há mar sem rio, eu já falei. (p. 90)

Segundo a perspectiva da personagem, o mar é o resultado dos rios, diversos como as etnias, usos e costumes de Angola. Ele é a síntese da terra. Não se lhe opõe. Por isso é VIDA, alimento obtido pelo trabal ho e representa a solidariedade dos povos do mar e os do interior.

Ora, do ponto de vista que escolhemos para o breve exame da literatura angolana contemporânea, o percurso se completa: o fato colonial existiu, não pode ser negado. Mas o porto da "nossa terra de Luanda", como carinhosamente várias personagens dos textos angolanos se referem à capital do país, já tem sua própria voz e consolidou uma imagem própria. Agora pode prescindir do ponto de vista das caravelas e, triunfante, dizer que o mar também Ihe pertence e, assim, ver a si próprio como um dos pilares da ponte que une as várias margens desse NOSSO mar, o dos falantes da língua portuguesa.

\section{Referências Bibliográficas}

BAK HTIN, M.(V.N.VOLOCHÍNOV). Marxismo e filosofia da linguagem. Trad. M .Lahud, Y.

F. Vieira. 2 ed. São Paulo: Hucitec, 1981.

BOSI, A. Dialética da colonização. São Paulo: Ática, 1992.

NETO, A. Náusea. In SANTILLI, M.A. Estórias africanas. São Paulo: Ática, PEPETELA. O cão e os calús. Luanda: União escritores angolanos, 1988.

PEPETELA. O desejo de Kianda. Lisboa: Dom Quixote, 1995.

RUI, M. Rioseco. Lisboa: Cotovia, 1977.

SECCO, C.L.T. (Coord) et alii. Antologia do mar na poesia africana de língua portuguesa.

vol. I: Angola. Rio de J aneiro: Letras, UFRJ , 1996.

VIEIRA, J osé Luandino. Macandumba. Lisboa: Edições 70, 1978. 